\title{
G-protein coupled estrogen receptor 1 expression in rat and human heart: Protective role during ischaemic stress
}

\author{
VANLATA H. PATEL ${ }^{1}$, JING CHEN ${ }^{1}$, MANJUNATH RAMANJANEYA ${ }^{1}$, EMMANOUIL KARTERIS ${ }^{2}$, \\ ELENA ZACHARIADES ${ }^{2}$, PETER THOMAS ${ }^{3}$, MARTIN BEEN $^{1}$ and HARPAL S. RANDEVA ${ }^{1}$ \\ ${ }^{1}$ Endocrinology and Metabolism Group, Clinical Sciences Research Institute, Warwick Medical School, \\ University of Warwick, Coventry CV4 7AL; ${ }^{2}$ Centre for Cell and Chromosome Biology, Biosciences, Brunel University, \\ Uxbridge UB8 3PH, UK; ${ }^{3}$ Marine Science Institute, University of Texas at Austin, Port Aransas, TX 78373, USA
}

Received January 25, 2010; Accepted February 16, 2010

DOI: 10.3892/ijmm_00000452

\begin{abstract}
G-protein coupled estrogen receptor 1, GPER, formerly known as GPR30, is a seven transmembrane domain receptor that mediates rapid estrogen responses in a wide variety of cell types. To date, little is known about the role of GPER during ischaemia/reperfusion injury. In this study, we report both mRNA and protein expression of GPER in the rat and human heart. The role of GPER in estrogen protection against ischaemic stress in the rat heart was also assessed using the isolated Langendorff system. Pre-treatment with $17 ß$-estradiol (E2) significantly decreased infarct size, $(61.48 \pm 2.2 \%$ to $27.92 \pm 2.9 \%(\mathrm{P}<0.001)$. Similarly, treatment with the GPER agonist G1 prior to 30 -min global ischaemia followed by 120 -min reperfusion significantly reduced infarct size from $61.48 \pm 2.2 \%$ to $23.85 \pm 3.2 \%(\mathrm{P}<0.001)$, whilst addition of GPR30 antibody, abolished the protective effect of G1 (infarct size: $55.42 \pm 1.3 \%$ ). The results suggest that GPER under cardiac stress exerts direct protection in the heart and may serve as a potential therapeutic target for cardiac drug therapy.
\end{abstract}

\section{Introduction}

Estrogens play critical regulatory roles in the physiology and development of numerous organs through binding to specific receptors (1). The female reproductive system, including the uterus and the breast, are major targets of estrogen actions. In addition, estrogens act on non-reproductive organs such as the brain, liver, and heart. Epidemiological studies have documented a lower incidence of coronary heart disease in premenopausal women compared with age-matched postmenopausal women and compared with men, suggesting a

Correspondence to: Dr Harpal S. Randeva, Endocrinology and Metabolism Group, Clinical Sciences Research Institute, Warwick Medical School, University of Warwick, Coventry CV4 7AL, UK E-mail: harpal.randeva@warwick.ac.uk

Key words: G-protein coupled estrogen receptor 1, G1, hypoxia, cardioprotection, cardiac ischaemia protective role of estrogens at the cardiac level $(2,3)$. This cardioprotective effect has been further corroborated in rodent models (4-8). Two isoforms of nuclear estrogen receptors termed ER $\alpha$ and ERß mediate genomic responses to estrogens, and have distinct, non-overlapping physiological functions. Upon activation, the ligand-activated nuclear estrogen receptor dimerises and can directly interact with estrogen response elements in the promoter region of target genes, leading to activation/repression of gene transcription (9-12).

Over the past 20 years many research groups have shown that steroids also act at the cell surface of many target tissues and cell types to initiate rapid responses, via binding to membrane receptors, that frequently do not involve changes in gene transcription (13). GPER represents a third ER in addition to the classical nuclear ER isoforms ER $\alpha$ and ERß. GPER, previously known as GPR30, has been cloned by several research groups initially as an orphan G-protein coupled receptor (GPCR) with a wide distribution in both reproductive and nonreproductive tissues (14-17). Filardo and co-workers suggested that GPER may be associated with estrogen signalling based on their finding that estrogens caused rapid activation of signalling pathways in a breast cancer cell line (SKBR3 cells) that do not express ERs but express GPER (18). Subsequently it was demonstrated independently by two research groups that recombinant GPER has the binding characteristics of a membrane estrogen receptor $(19,21)$, and activates multiple signalling pathways upon estrogen stimulation (20).

The GPER protein is present both on the plasma membrane and intracellularly in target cells. GPER is localised on the cell surface and binds E2-BSA-FITC and activates a stimulatory G-protein $\left(\mathrm{G}_{\mathrm{s}}\right)$ leading to activation of adenylyl cyclase and increase in intracellular levels of cAMP (18-20). GPR30 also appears to be expressed intracellularly where it can induce calcium mobilization and synthesis of phosphatidylinositol 3,4,5-trisphosphate $(21,22)$. In 2006, Prossnitz and co-workers identified the first GPER-specific ligand, G1, which has a high affinity for GPER (Ki: $11 \mathrm{nM}$ ) but does not exhibit any binding affinity for ER $\alpha$ or ERß (23). This specific agonist provides new opportunities to characterize and determine the functional significance of GPER using in vitro and in vivo models. 
Recently, it has been shown that G1 plays a cardioprotective role in rats during myocardial ischemia-reperfusion (24). In this study, a reduction of post-ischaemic contractile dysfunction was noted in rats treated with $\mathrm{G} 1$, when compared with untreated controls. Moreover, G1-treated animals exhibited reduced infarct size compared with untreated controls. These effects did not show any sexual dimorphism and involved a PI3 Kinase (PI3K)-dependent pathway; since addition of wortmannin (a PI3K inhibitor) blocked G1 effects in this experimental model (24). In another study that corroborated the cardioprotective effects of G1, Bopassa et al, demonstrated that G1 inhibited the mitochondria permeability transition pore (mPTP) opening, involving an ERK1/2-specific pathway (25).

To date, very little is known abut the role of GPER in the human heart. Interestingly, activation of GPER led to a lowering of blood pressure in human arterial blood vessels (26). We hypothesised that GPER can mediate estrogen responses at the cardiac level, acting as a regulator of cardiovascular pathophysiology. Therefore, in this study we investigated the expression of GPER in the various compartments of the human and rat heart and assessed the effects of $\mathrm{G} 1$ and $\mathrm{E} 2$ in the rat heart during ischaemia.

\section{Materials and methods}

Animals and materials. All experiments were carried out in accordance with the United Kingdom Home Office Guide on the Operation of Animal (Scientific Procedures) Act of 1986, UK. All reagents used were of the highest purity commercially available. The G1 ligand was obtained from Calbiochem (Germany), heart sections from AMS Biotechnology (Europe), GPER (GPR30) antibody from Santa Cruz Biotechnology Inc. (CA, USA), and $17-\beta$ estradiol and triphenyltetrazolium chloride (TTC) from Sigma-Aldrich (UK).

Human cardiovascular multiple tissue cDNA (MTC) panel. A commercially available human cardiovascular multiple tissue cDNA (MTC) panel was obtained from Clontech (Oxford, UK). All tissues were normal (i.e. non-diseased) from individuals ranging from 11 up to 32 years of age. Primer sequences for RT-PCR amplification of human GPER gene were: sense 5'-CTGCACGAGCGGTACTACGA-3' and antisense 5'-CAGATGAGGCCACAGCTCAG-3'. Quantitative expression of GPER in human heart was assessed by quantitative PCR (Q-PCR) on an ABI7400 instrument (Applied Biosystems) using $\mathrm{SYBR}^{\circledR}$ Green-PCR reaction mixture (Sigma-Aldrich). ß-actin primers sense 5'-AAGAGAGGC ATCCTCACCCT-'3 and antisense 5'-ACATGGCTGGG GTGTTGAA-'3 were used as controls. As a negative control for all the reactions, distilled water was used in place of the cDNA. The RNA levels were expressed as a 'relative quantification' (RQ) value, using 'Delta Ct method' for comparing relative expression results between treatments in Q-PCR.

Immunofluorescent analysis. Tissue sections were left to warm at room temperature for $5 \mathrm{~min}$, and then fixed with pre-cooled fixative (acetone) at $-20^{\circ} \mathrm{C}$ for $5 \mathrm{~min}$, at room temperature. Sections were rinsed 3 times in PBS, followed by incubation with $10 \%$ bovine serum albumin (BSA) for $1 \mathrm{~h}$. Tissue cells were incubated for $1 \mathrm{~h}$ with antibodies against
GPR30 (Santa Cruz Biotechnology) at a 1:200 dilution in 1\% BSA/PBS. Tissues were then washed with PBS prior to incubation with anti-rabbit TRITC-conjugated antibody (Santa Cruz Biotechnology) for $1 \mathrm{~h}$. Slides were washed with PBS and mounted in Vectashield ${ }^{\circledR}$ mounting medium (Vector Labs) containing the dye 4,6-diamido-2-phenylindole (DAPI) to counterstain the nuclei. Images were captured using a Plan Apo Neofluor 63X NA 1.25 oil objective (Zeiss) on a Zeiss Axiovert $200 \mathrm{M}$ microscope and viewed using AxioVision software. Images were taken at a set exposure time.

\section{Rat heart cDNA extraction and amplification of GPER gene} Normal rat heart. Adult male Wistar rats weighing 250-300 g were sacrificed using cervical dislocation. Total RNA from different rat heart chambers was extracted and cDNA synthesis was performed as previously described (27).

Hypoxic rat heart. Adult male Wistar rats weighing 250$300 \mathrm{~g}$ were sacrificed using cervical dislocation. Hearts were rapidly excised, immersed in ice-cold oxygenated Tyrode's solution. The hearts were perfused via the aortic cannula in the modified Langendorff mode with Tyrode's solution ( $\mathrm{Na} 138 \mathrm{mM}$, K $4.0 \mathrm{mM}$, Ca $1.8 \mathrm{mM}, \mathrm{Mg} 1.0 \mathrm{mM}$, $\mathrm{HCO}_{3} 24.0 \mathrm{mM}, \mathrm{H}_{2} \mathrm{PO}_{4} 0.4 \mathrm{mM}, \mathrm{Cl} 121 \mathrm{mM}$, glucose $11 \mathrm{mM}$ ). The $\mathrm{pH}$ of the solution was maintained at 7.4 by continuously bubbling with $95 \% \mathrm{O}_{2}, 5 \% \mathrm{CO}_{2}$ and temperature was maintained at $37^{\circ} \mathrm{C}$. A constant perfusion rate of $10 \mathrm{ml} / \mathrm{min}$ was maintained using a Gilson Minipuls 2 peristaltic pump (Gilson Inc., OH, USA). Contractile parameters were measured by inserting a fluid-filled latex balloon through the left atrium into the left ventricular chamber, the balloon was connected to a pressure transducer (MTL0380, ADInstruments Ltd., UK) and the balloon volume was adjusted to give end-diastolic pressure of $<10 \mathrm{mmHg}$. Aortic perfusion pressure was monitored with a second pressure transducer in series with the aortic cannula. Data were continuously recorded using a Power Lab 8 preamplifier/digitiser (ADInstruments Ltd.). All hypoxic heart experiments lasted a total of $75 \min (n=3)$. Hearts were allowed to stabilize for $30 \mathrm{~min}$ with the standard oxygenated Tyrode's perfusion followed by 30 -min hypoxia. Hypoxic conditions were obtained by reducing the oxygen partial pressure in the Tyrode's solution, nitrogen being substituted for oxygen in the gas mixture $95 \% \mathrm{~N}_{2} 5 \% \mathrm{CO}_{2}$. The hearts were maintained in a closed thermo-controlled chamber $\left(37^{\circ} \mathrm{C}\right)$ throughout the hypoxia treatment. The hypoxic period was followed by perfusion with oxygenated Tyrode (re-oxygenation). Left ventricular samples were collected at stabilisation, 30-min hypoxia and 30-min re-oxygenation. All samples were snap-frozen in liquid nitrogen and stored at $-80^{\circ} \mathrm{C}$ until further analysis.

Polymerase chain reaction (PCR). The sets of primers used for RT-PCR amplification of rat GPER gene were sense 5'-CCTCATCTTGGTGGTGAACA-3' and antisense 5'-TAC TGCCGTCCAGGTTGAA-3', ß-actin sense 5'-AAGAGAG GCATCCTCACCCT-3' and antisense 5'-TACATGGCT GGGGTCTTGAA-3'. Quantitative PCR was performed on a Roche Light Cycler ${ }^{\mathrm{TM}}$ system (Roche Molecular Biochemicals, Manheim, Germany). PCR reactions were carried out in a reaction mixture consisting of $5 \mu \mathrm{l}$ Master mix containing 


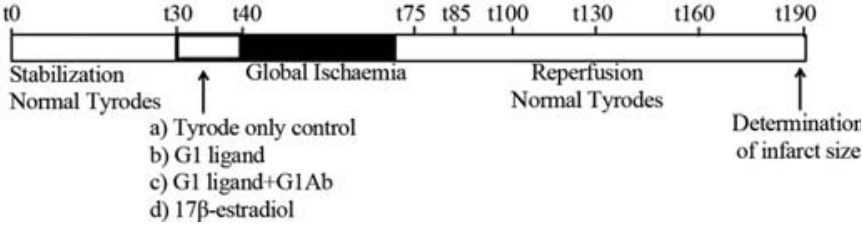

Figure 1. A schematic representation of the experimental protocol using the Langendorff system to determine infarct size.

$2 \mathrm{mM} \mathrm{MgCl}{ }_{2}$ (Biogene, $\mu \mathrm{l}$ of cDNA, Kimbolton, UK), $1 \mu \mathrm{l}$ of sense and antisense primers (50 ng/ $\mu 1), 2.5$ liters of Light Cycler and $0.5 \mu 1$ DNA Master SYBR ${ }^{\circledR}$ Green I (Roche, Mannheim, Germany), using a protocol as previously described (25). The PCR products from all samples were purified from the $1 \%$ agarose gel using the QIAquick gel extraction kit (Qiagen). PCR products were then sequenced in an automated DNA sequencer, and the sequence data were analyzed using Blast Nucleic Acid Database Searches from the National Centre for Biotechnology Information, confirming the identity of the products.

Western blotting. Protein lysates were prepared by homogenizing rat heart tissue in RIPA lysis buffer (Santa Cruz Biotechnology Inc.). Protein concentrations in the lysates were measured using the Bradford method for sample preparation, equal amounts of Laemmli buffer (5 M urea, 0.17 M SDS, $0.4 \mathrm{M}$ dithiothreitol, and $50 \mathrm{mM}$ Tris- $\mathrm{HCl}, \mathrm{pH}$ 8.0) were added, and samples denatured by sonication and boiling. Samples were separated by SDS-PAGE (10\% resolving gel) and transferred to polyvinylidene difluoride (PVDF) membranes at $100 \mathrm{~V}$ for $1 \mathrm{~h}$ in a transfer buffer containing $20 \mathrm{mM}$ Tris, $150 \mathrm{mM}$ glycine, and 20\% methanol. The PVDF membranes were incubated with primary antibody for GPER (Santa Cruz Biotechnology Inc.) at a 1:1000 dilution in Tris buffered saline (TBS)-0.1\% Tween (TBST), and 5\% BSA overnight at $4{ }^{\circ} \mathrm{C}$. The membranes were washed, incubated with a secondary anti-goat horseradish peroxidase-conjugated antibody (1:2000, Santa Cruz Biotechnology Inc.) for $1 \mathrm{~h}$ at room temperature, and washed for $60 \mathrm{~min}$ with TBST. Antibody complexes were visualized using chemiluminescence. The densities were measured using a scanning densitometer coupled to Scion Image scanning software (Scion Corp., Frederick, MD, USA). In addition to quantitative loading of gels, membranes were also re-probed with the B-actin antibody (Cell Signalling Technology Inc., Beverly, MA, USA; 1 in 10,000 dilutions) to determine protein loading.

Determination of infarct size. As described above, rat hearts were isolated and perfused on the Langendorff system. A schematic representation of the experimental protocol is shown in Fig. 1, lasting a total of $190 \mathrm{~min}$. Hearts were allowed to stabilize for $30 \mathrm{~min}$ with the standard Tyrode's perfusion. Contractile parameters (left ventricular systolic pressure, LVSP $\mathrm{mm} \mathrm{Hg}$ and left ventricular end diastolic pressure, LVEDP $\mathrm{mm} \mathrm{Hg}$ ) were measured at $\mathrm{t} 0, \mathrm{t} 30, \mathrm{t} 40 \mathrm{t} 75, \mathrm{t} 85, \mathrm{t} 100$, $\mathrm{t} 130, \mathrm{t} 160, \mathrm{t} 190 \mathrm{~min}$ and the difference between these two pressure values represented the left ventricular developed pressure (LVDP, mm Hg). The heart rate (HR, beats/min) was determined at the same time and rate pressure product (RPP, $\mathrm{mm} \mathrm{Hg}$ ) was calculated by multiplying the LVDP by
A.

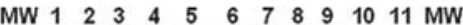

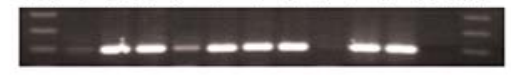

B.
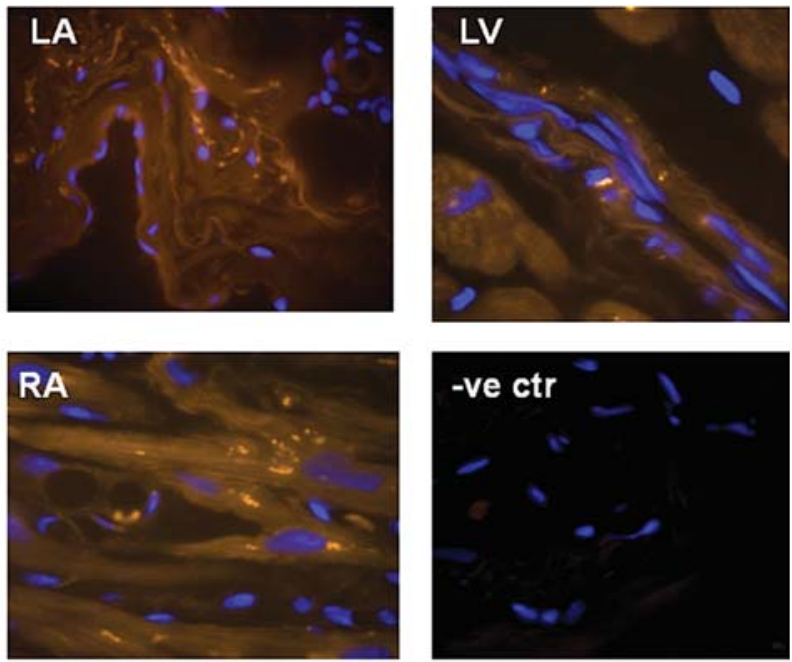

C.

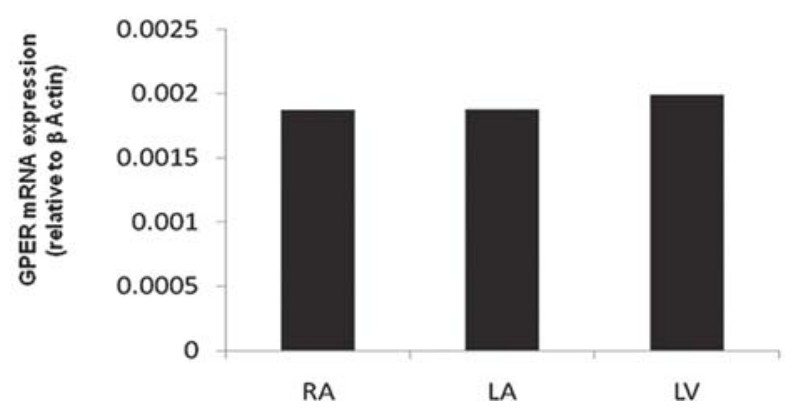

Figure 2. Expression of cardiac GPER mRNA. (A) RT PCR analysis of human heart cDNA panel. MW, molecular weight ladder; lane 1 , atrioventricular node; 2 , right ventricle; 3 , left ventricle; 4, AV sinus; 5 , avriet dextra; 6, right atrium; 7, left atrium; 8, apex; 9, aorta; 10, whole heart; 11, water (negative control). (B) Immunofluorescent analysis of human cardiac sections, revealed strong expression of GPER at protein level in left atrium (LA), and right ventricle (RV) with right atrium (RA). Negative control (cardiac section incubated without GPER primary antibody) demonstrates specificity of GPER staining. (C) Quantitative RT-PCR analysis revealed no apparent differences in GPER expression in RA, LA and LV cDNAs from human heart.

the HR. RPP is an accurate measure of mechanical function of the heart and total myocardial energy turnover. All measurements recorded after a $30-$ min stabilisation period was considered as the baseline values ( $\mathrm{t} 0)$. Global ischaemia was produced for $30 \mathrm{~min}$ by closing the inflow of physiological solution. The hearts were maintained in a thermo-controlled chamber $\left(37^{\circ} \mathrm{C}\right)$ throughout the protocol. The ischaemic period was followed by reperfusion lasting $120 \mathrm{~min}$. At the conclusion of the experiment hearts were frozen at $-20^{\circ} \mathrm{C}$ and sliced into $2-\mathrm{mm}$ transverse sections and incubated in $1 \%$ triphenyl-

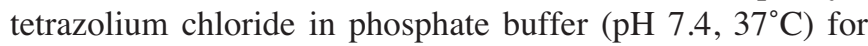
$15 \mathrm{~min}$. Viable tissue stained red and infarcted tissue remained pale. The sections were fixed in $4 \%$ formalin for $24 \mathrm{~h}$ before infarct size was determined (28). The size of infarcted area was determined by the volume and weight method (29).

Experimental study groups. Hearts from male Wistar rats were divided among the following experimental groups: a) control 


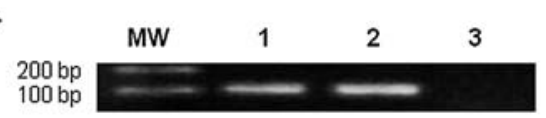

B.

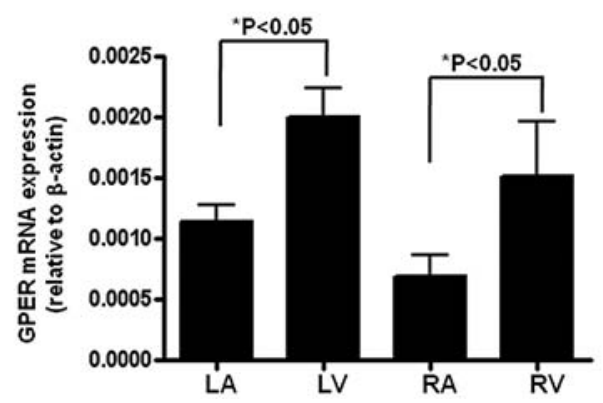

C.

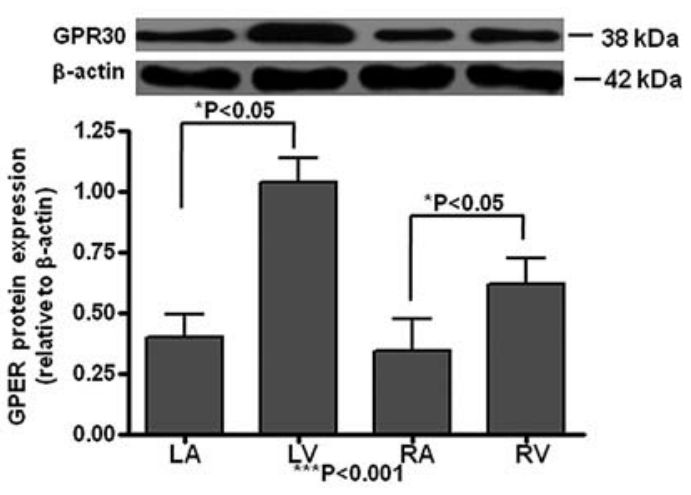

D.

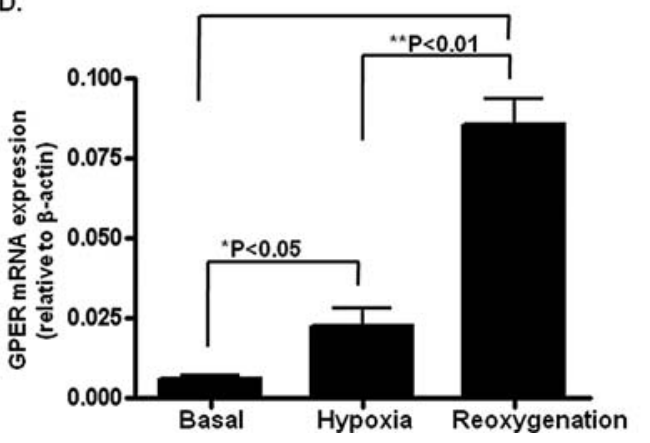

Figure 3. (A) RT-PCR analysis of GPER mRNA. MW, molecular weight ladder; lane 1, rat whole heart; 2, rat hypothalamus (positive control); 3, water (negative control). (B) Quantitative mRNA expression of GPER in rat heart chambers. LA, left atrium; LV, left ventricle; RA, right atrium; RV, right ventricle. (C) Western blot analysis of GPER protein expression in rat heart chambers. (D) Changes in GPER mRNA expression during cardiac stress.

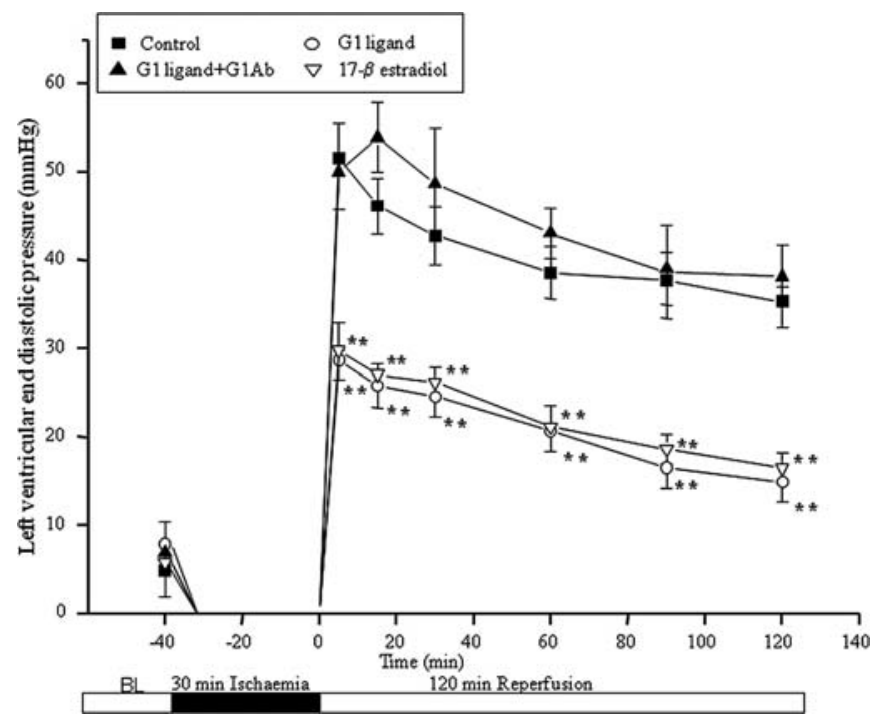

Figure 4. Post-ischaemic recovery following a period of 30-min global ischaemia followed by 120 -min reperfusion, on cardiac work, rate pressure product (RPP). ${ }^{* *} \mathrm{p}<0.01$ for groups treated with G1 ligand, $17-\beta$ estradiol vs. control, G1 ligand+G1 Ab.

$(\mathrm{n}=10)$; b) GPR30 ligand, G1 (100 nM, n=10); c) GPR30 ligand G1 plus GPR30 antibody, G1Ab (1 nM, n=5); d) 17- $\beta$ estradiol (100 nM, n=5). All hearts were subjected to 30-min global ischemia and 120-min reperfusion.

Statistical analysis. All results are expressed as mean \pm SEM. Statistical analyses between groups were performed using

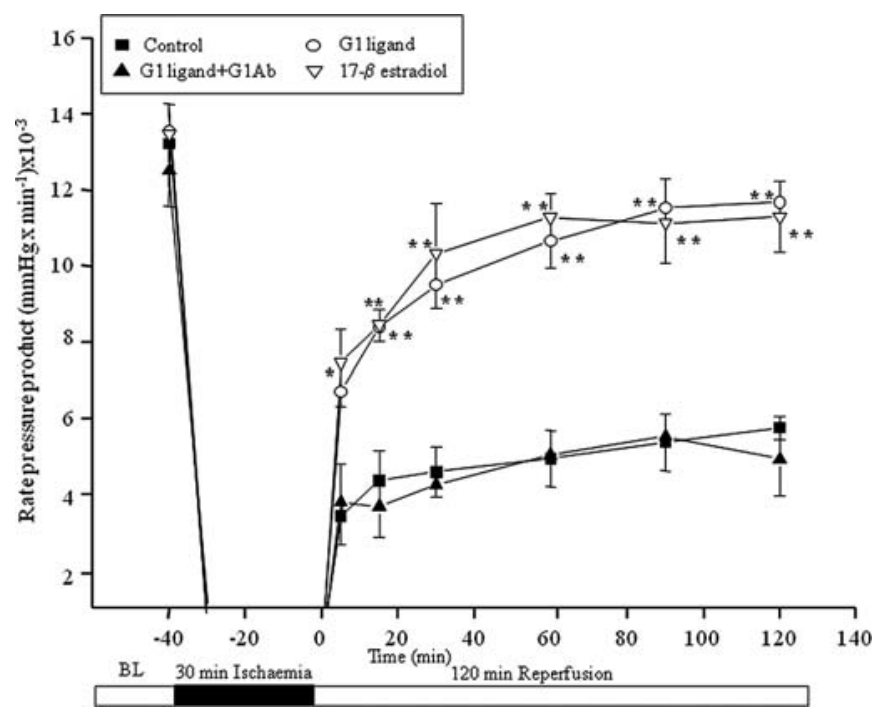

Figure 5. Post-ischaemic recovery following a period of 30-min global ischaemia and 120-min reperfusion, on functional recovery of LVEDP (mmHg). ${ }^{* *} \mathrm{p}<0.01$, represents G1 ligand, 17- 3 estradiol vs. control and G1 ligand+G1 $\mathrm{Ab}$.

one-way ANOVA followed by Bonferroni's post hoc test for significance. $\mathrm{P}<0.05$ was considered significant.

\section{Results}

Expression of GPER in human heart. GPER mRNA and protein was detected in various compartments of the adult human 
A.

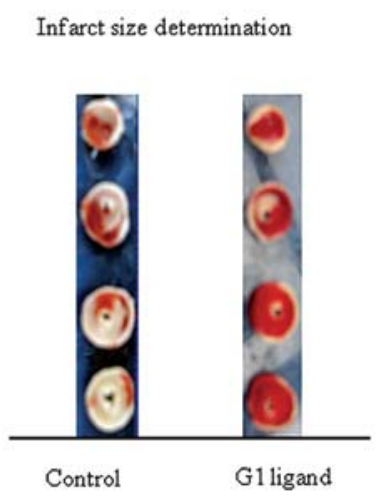

B.

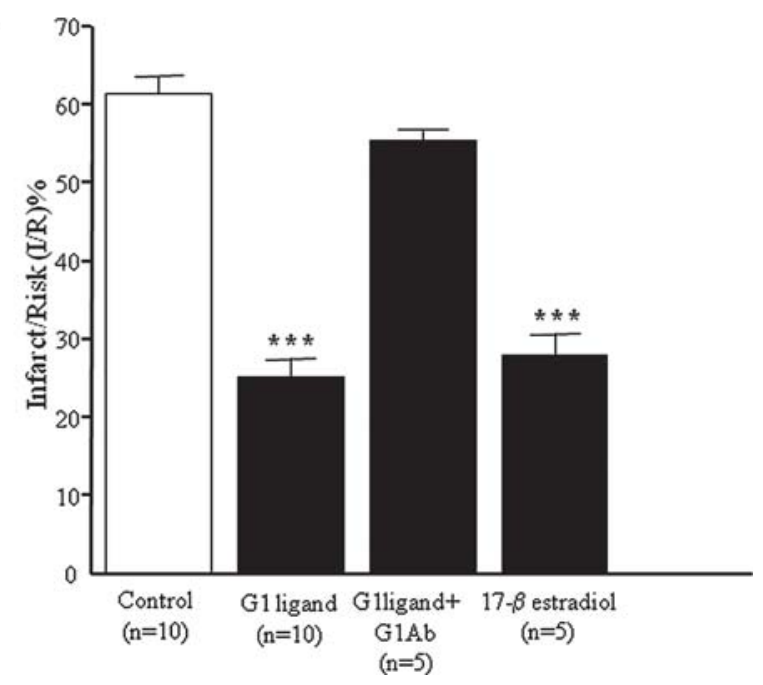

Figure 6. (A) Images of transverse sections of rat hearts. Infarct size was determined using triphenyltetrazolium chloride (TTC). Infarcted tissue appears pale, whilst viable tissue stains red. Only control group and pre-treatment with G1 ligand are represented in this example. (B) Graph representing in vitro myocardial infarct size expressed as a percentage of the risk zone. Results are presented as mean $\pm \mathrm{SEM},{ }^{* * *} \mathrm{P}<0.001, \mathrm{G} 1$ ligand, $17-\beta$ estradiol treated groups vs. control, G1 ligand+G1Ab.

heart by RT-PCR and Western blot analyses, respectively (Fig. 2). Analysis of a human cardiovascular multiple tissue cDNA panel showed GPER is expressed in the following compartments: right and left ventricle and atrium, AV sinus, avriet dextra, and aorta, but is not detected in the atrioventricular node and apex (Fig. 2A). Immunofluorescent analysis using a GPER specific antibody revealed strong cytoplasmic and membrane staining of GPER in the left atrium (LA), left ventricle (LV) and right atrium (RA; Fig. 2B). Quantitative RT-PCR analysis revealed that there are no apparent differences in the expression of GPER when cDNA from LA was compared to LV and RA (Fig. 2C).

GPER is differentially expressed in the rat heart. RT-PCR analysis using hypothalamic cDNA as positive control, showed that GPER is expressed in the rat heart (Fig. 3A). Quantitative RT-PCR analysis showed differential GPER mRNA expression levels in the rat heart with significantly higher amounts in the left ventricle (LV) compared to the left atrium (LA), and in the right ventricle (RV) compared to the right atrium (RA) (Fig. 3B). Western blot analysis further confirmed the presence of the GPER protein in the rat heart. Moreover using semi-quantitative Western blotting and correcting over $\beta$-actin, we demonstrate that the differential expression of the GPER protein in LA, LV, RA and RV mirrors that of the GPER gene (Fig. 3C).

In addition, we evaluated the expression of GPER mRNA during hypoxic stress using the isolated Langendorff perfused rat heart model. LV tissue samples were collected during stabilisation, 30-min hypoxia and 30-min reoxygenation. Using quantitative RT-PCR analysis changes in the expression of GPER mRNA were observed. Hypoxia resulted in a 2.4-fold increase in GPER mRNA compared to basal conditions. Furthermore, within the first 30 min of reoxygenation there was a substantial further significant increase of GPER mRNA expression, reaching 10.3 fold that under basal conditions (Fig. 3D).
Left ventricular function in the rat heart. The left ventricular developed pressure (LVEDP) is a sensitive and reliable measure of ischemic damage and a key determinant of myocardial recovery during reperfusion (30). Groups treated with G1 ligand and 17- $\beta$ estradiol demonstrated a significant reduction in ischemic injury and an improved recovery on reperfusion compared to the control and G1 ligand $+\mathrm{G} 1 \mathrm{Ab}$ treated groups (Fig. 4, $\mathrm{P}<0.01$ ).

Poor recovery of the mechanical function of the heart (RPP) following 30-min global ischemia was observed during reperfusion in the control group, whereas pre-treatment with G1 ligand significantly improved the recovery of cardiac function during reperfusion (Fig. 5). Furthermore, myocardial preservation seen with G1 ligand pre-treatment on functional recovery was lost when hearts were pre-treated with G1 ligand $+\mathrm{G} 1 \mathrm{Ab}$ (Fig. 5). G1Ab on its own showed no change on functional recovery of the hearts compared to the control group (data not shown).

Effect of G1 on infarct size. Infarct size was determined using triphenyltetrazolium chloride (TTC) staining. Infarcted tissue appears pale, whilst viable tissue stains red. Images from transverse sections of rat hearts, revealed a viable pattern (red colour) in those treated with G1 when compared with the control group (white colour, Fig. 6A). The total area of infarction was determined by the volume and weight method (29). The total area at risk (R) of myocardial infarction was comparable between all the treatment groups (data not shown).

Pre-treatment with G1 ligand 10 min prior to global ischemia and reperfusion, significantly reduced infarct size $(23.85 \pm 3.2 \%)$ compared to the untreated controls $(61.48 \pm 2.2 \%)$ (Fig. 6B, P<0.001). However, pre-treatment with G1 ligand $+\mathrm{G} 1 \mathrm{Ab}$, showed no significant reduction in infarct size (Fig. 5B, 55.42 $\pm 1.3 \%, \mathrm{P}=\mathrm{NS}$ ). In addition, pre-treatment with $17-\beta$ estradiol alone exerted significant myocardial protection (Fig. 6B, 27.92 $\pm 2.9 \%, \mathrm{P}<0.001$ ). Furthermore, pre-treatment 
with G1Ab alone showed no change in infarction compared to control (results not shown).

\section{Discussion}

In this study, we demonstrate for the first time that GPER is expressed in numerous cardiac compartments of the human heart at the gene level. GPER mRNA is expressed in all the chambers of the human heart and also in the AV sinus, avriet dextra, and aorta, but is not present in the atrioventricular node and apex. The abundance of the GPER transcript was similar in the right atrium, left atrium and left ventricle in the single human heart sample analyzed. In contrast, quantitative RT-PCR analysis revealed that in the rodent model GPER is upregulated at both the gene and protein level in the LV compared to the LA, and in the RV compared to RA. In addition, GPER is differentially expressed during cardiac stress, when the hypoxic Langengorff perfused rat heart model is used. Hypoxia results in an increase in GPER expression and upon reoxygenation the expression in even greater. These data clearly demonstrate the functional importance of GPER during the early phase of reperfusion. Our findings are consistent with those of previous studies demonstrating that mediators of myocardial protection target the start of reperfusion in order to limit cell death via reducing necrosis and apoptosis $(31,32)$.

In order to dissect further the cardioprotective role of GPER, perfused hearts were treated with the GPER-specific ligand G1 in the presence or absence of GPER antibody. Given that experimental procedures were carried out in intact hearts, we could not use the siRNA approach to demonstrate receptor specificity. However, in vitro incubations with a receptorspecific antibody has been used extensively to study the involvement of receptors in mediating the effects of specific ligands in pharmacological studies.

Administration of G1 prior to global ischemia reperfusion dramatically reduced myocardial infarct size in the isolated rat infarction model. In line with this observation, the cardioprotective effect induced by the G1 ligand resulted in an increase in functional recovery of contractility following myocardial ischaemia/reperfusion. The exact mechanism of this protective effect on diastolic function is not fully elucidated. However, it is attractive to speculate that such an effect could be due to improved metabolic function of the myocardium. Furthermore, the G1 ligand-treated group demonstrated an improved recovery of RPP. These data suggest that both the impulse-generating system and contractile cells are better preserved following G1 ligand treatment. These responses are mediated via activation of GPER, since incubation of hearts with a GPER antibody abolished the G1 response.

Collectively, our data suggest that GPER exerts cardioprotective properties. While this manuscript was under preparation, another study was published which supports our findings (24). In this study, it was shown that G1 activation of GPER improves functional recovery and reduces infarct size in isolated rat hearts following ischemia and reperfusion through a PI3K-dependent mechanism. However, no previous studies have reported on the distribution of GPER in the human heart. The present results show that GPER is also strongly expressed in the major components of the human heart, suggesting that GPER-mediated estrogen pathways may have a similar protective role in humans.

Our findings point towards another potential estrogenmediated cardioprotective mechanism involving a distinct pathway from that of ERs. Moreover, these observations provide a basis for the generation of novel therapeutic approaches at the cardiac level. This is of increasing importance since the results of recent epidemiological studies have challenged the prevailing view that hormone replacement therapy has a protective effect. For example, numerous clinical trials have linked estrogen therapy with increased venous complications (33-37). These complications could be due to activation of multiple pathways that act at at the genomic and non-genomic levels. For example, it has been reported that 17- $\beta$ estradiol, 4-hydroxytamoxifen, and IC1182,780 also bind to GPER and can act as estrogen agonists by activating GPER-mediated signaling pathways (19).

In conclusion, these findings provide better insight into the possible therapeutic potential for GPER and its ligand G1. Further research is needed into the divergent actions of estrogen-based therapeutic compounds acting in a genomic and non-genomic manner at the cardiac level. This will not only lead to the generation of novel hypotheses regarding cardioprotective roles of steroids, but also to the generation of novel therapeutic agents of higher efficacy and selectivity.

\section{Acknowledgements}

This study was supported by the John Kennedy Research Fund, and by a National Institutes of Health Grant ESO12961.

\section{References}

1. Chaudhuri G: Nuclear receptors and female reproduction: a tale of 3 scientists, Jensen, Gustafsson and O'Malley: Reprod Sci 15: 110-120, 2008.

2. Barret-Connor E: Sex differences in coronary heart disease: Why are women so superior? The 1995 Ancel Keys Lecture. Circulation 95: 252-264, 1997

3. Crabbe DL, Dipla K, Ambati S, Zafeiridis A, Gaughan, JP Houser SR and Margulies KB: Gender differences in postinfarction hypertrophy in end-stage failing hearts. J Am Coll Cardiol 41: 300-306, 2003.

4. Zhai P, Eurell TE, Cotthaus R, Jeffery EH, Bahr JM and Gross DR: Effects of estrogen on global myocardial ischaemiareperfusion injury in female rats. Am J Physiol Heart Circ Physiol 279: 2766-2775, 2000.

5. Xu Y, Arenas IA, Armstrong SJ, Plahta WC, Sandra HX and Davigge ST: Estrogen cardiac recovery after ischaemia/ reperfusion by decreasing tumour necrosis factor-alpha. Cardiovasc Res 69: 777-780, 2006.

6. Beer S, Reincke M, Kral M, Callies F, Stromer H, Dienesch C, Steinhauer S, Ertl G, Allolio B and Neubauer S: High dose 17 beta estradiol treatment prevents development of heart failure post-myocardial infarction in the rat. Basic Res Cardiol 102: 9-18, 2007.

7. Wang T, Tsai BM, Reiger KM, Brown JW and Meldrum DR: 17 beta-estradiol decreases p38 MAPK-medited myocardial inflammation and dysfunction following acute ischemia. J Mol Cell Cardiol 40: 205-212, 2006.

8. Node K, Kitakaze M, Kosaka H, Minamino T, Sato H, Kuzuya T and Hori $\mathrm{M}$ : Role of $\mathrm{NO}$ and $\mathrm{Ca}^{2+}$ activated $\mathrm{K}^{+}$channels in coronary vasodilation induced by 17 beta estradiol in ischemic heart failure. FASEB J 11: 793-799, 1997.

9. Hall JM, Caurse JF and Korach KS: The multifaceted mechanisms of estradiol and estrogen receptor signalling. J Biol Chem 76: 36869-36872, 2001. 
10. Shao D, Berrodin TJ, Manas E, Hauze D, Powers R, Bapat A, Gonder D, Winneker RC and Frail DE: Identification of novel estrogen receptor alpha antagonists. J Steroid Biochem Mol Biol 88: 351-360, 2004.

11. Nilsson S, Makela S, Treuter E, Tujague M, Thomen J, Andersson G, Enmark E, Pettersson K, Warner M and Gustafsson JA: Mechanisms of estrogen action. Physiol Rev 4: 1535-1565, 2001.

12. McDonnel DP, Connor CE, Wijayaratna A, Chang CY and Norris TD: Definition of the molecular and cellular mechanisms underlying the tissue selective agonist/antagonist activities of selective estrogen receptor modulators. Recent Prog Horm Res 57: 295-316, 2002.

13. Falkenstein E, Tillmann HC, Christ M, Feuring M and Wehling M: Multiple actions of steroid hormones - a focus on rapid, nongenomic effects Pharmacol Rev 52: 513-556, 2000.

14. Carmeci C, Thompson DA, Ring HZ, Francke U and Weigel RJ: Identification of a gene (GPR30) with homology to the G-protein coupled receptor superfamily associated with estrogen receptor expression in breast cancer. Genomics 45: 607-617, 1997.

15. O'Dowd BF, Nguyen T, Marchese A, Cheng R, Lynch KR, Heng HH, Kolakowski LF Jr and George SR: Discovery of three novel G-protein coupled recepror genes. Genomics 47: 310-313, 1998.

16. Owman C, Blay P, Nilsson C and Lolait SJ: Cloning of human cDNA encoding a novel heptahelix receptor expressed in Burkitt's lymphoma and widely distributed in brain and peripheral tissues. Biochem Biophys Res Commun 228: 285-292, 1996.

17. Takada Y, Kato C, Kondo S, Korenaga R and Ando J: Cloning of cDNAs encoding $\mathrm{G}$ protein-coupled receptor expressed in human endothelial cells exposed to fluid shear stress. Biochem Biophys Res Commun 240: 737-741, 1997.

18. Filardo E, Quinn J, Pang Y, Graeber C, Shaw S, Dong J and Thomas P: Activation of the novel estrogen receptor $\mathrm{G}$ proteincoupled receptor 30 (GPR30) at the plasma membrane. Endocrinology 148: 3236-3245, 2007.

19. Thomas P, Pang Y, Filardo EJ and Dong J: Identity of an estrogen membrane receptor coupled to a $G$ protein in human breast cancer cells. Endocrinology 146: 624-632, 2005.

20. Filardo EJ and Thomas P: GPR30: a seven-transmembranespanning estrogen receptor that triggers EGF release. Trends Endocrinol Metab 16: 362-367, 2005.

21. Revankar CM, Cimino DF, Sklar LA, Arterburn JB and Prossnitz ER: A transmembrane intracellular estrogen receptor mediates rapid cell signaling. Science 307: 1625-1630, 2005.

22. Prossnitz ER, Oprea TI, Sklar LA and Arterburn JB: The ins and outs of GPR30: a transmembrane estrogen receptor. J Steroid Biochem Mol Biol 109: 350-353, 2008.

23. Bologa CG, Revankar CM, Young SM, Edwards BS, Arterburn JB, Kiselyov AS, Parker MA, Tkachenko SE, Savchuck NP, Sklar LA, Oprea TI and Prossnitz ER: Virtual and biomolecular screening converge on a selective agonist for GPR30. Nat Chem Biol 2: 207-212, 2006.

24. Deschamps AM and Murphy E: Activation of a novel estrogen receptor, GPER, is cardioprotective in male and female rats. Am J Physiol Heart Circ Physiol 297: 1806-1813, 2009.
25. Bopassa JC, Eghbali M, Toro L and Stefani E: A novel estrogen receptor GPER inhibits mitochondria permeability transition pore opening and protects the heart against ischemia/reperfusion injury. Am J Physiol Heart Circ Physiol 298: 16-23, 2010.

26. Haas E, Bhattacharya I, Brailoiu E, Damjanovic M, Brailoiu GC, Gao X, Mueller-Guerre L, Marjon NA, Gut A, Minotti R, Meyer MR, Amann K, Ammann E, Perez-Dominguez A, Genoni M, Clegg DJ, Dun NJ, Resta TC, Prossnitz ER and Barton M: Regulatory role of $\mathrm{G}$ protein-coupled estrogen receptor for vascular function and obesity. Circ Res 104: 288291,2009.

27. Karteris E, Machado RJ, Chen J, Zervou S, Hillhouse EW and Randeva HS: Food deprivation differentially modulates orexin receptor expression and signaling in rat hypothalamus and adrenal cortex. Am J Physiol Endocrinol Metab 288: 108910100, 2005.

28. Bose AK, Mocanu MM, Carr RD, Brand CL and Yellon DM: Glucagon-like peptide 1 can directly protect theheart against ischaemia/reperfusion injury. Diabetes 54: 146-151, 2005.

29. Sharma A and Singh M: Effect of ethylisopropyl amiloride, a $\mathrm{Na}^{+}-\mathrm{H}^{+}$exchange inhibitor, on cardioprotective effect of ischaemic and angiotensin preconditioning. Mol Cell Biochem 214: 31-38, 2000.

30. Ogino H, Smolenski RT, Zych M, Seymour AM and Yacoub MH: Influence of preconditioning on rat heart subjected to prolonged cardioplegic arrest. Ann Thorac Surg 62: 469-474, 1996.

31. Bhamra GS, Hausenloy DJ, Davidson SM, Carr RD, Paiva M, Wynne AM, Mocanu MM and Yellon DM: Metformin protects the ischemic heart by the Akt-mediated inhibition of mitochondrial permeability transition pore opening. Basic Res Cardiol 103: 274-284, 2008.

32. Bose AK, Mocanu MM, Carr RD and Yellon DM: Myocardial ischaemia-reperfusion injury is attenuated by intact glucagon like peptide-1 (GLP-1) in the in vitro rat heart and may involve the p70s6K pathway. Cardiovasc Drugs Ther 21: 253-256, 2007.

33. Losel RM, Falkenstein E, Feuring M, Schultz A, Tillmann HC, Rossol-Haseroth $\mathrm{K}$ and Wehling M: Non genomic steroid action: controversies, questions and answers. Physiol Rev 83: 965-1016, 2003.

34. Watters JJ, Chun TY, Kim YN, Bertics PJ and Gorski J: Estrogen modulation of prolactin gene expression requires an intact mitogen-activated protein kinase signal transduction pathway in cultured rat pituitary cells. Mol Endocrinol 14: 1872-1881, 2000.

35. Song RX, Santen RJ, Kumar R, Adam L, Jeng MH, Masamura S and Yue W: Adaptive mechanisms induced by long term estrogen deprivation in breast cancer cells. Mol Cell Endocrinol 193: 29-42, 2002.

36. Harlap S: The benefits and risks of hormone replacement therapy: an epidemiologic overview. Am J Obstet Gynecol 166: 1986-1992, 1992.

37. Colditz GA: Fat, estrogen, and the time frame for prevention of breast cancer. Epidemiology 3: 209-211, 1995. 